\title{
The organization of casualty and accident services
}

\author{
L. W. Aldridge \\ M.B., F.R.C.S. \\ Principal Assistant Senior Medical Officer, \\ Birmingham Regional Hospital Board, 146 Hagley Road, Birmingham, B16 9PA
}

LEST the title gives rise to misconception, may I say that officers of the Board are not the Board. This paper is given as a brief review of the advice received at the Board and of my own discussions as a medical officer of the Board. It is not a statement of Board policy. Policy has to be determined by the Board as a corporate body after receiving advice.

The approach of the Department of Health to this problem has been put by the previous speaker, Dr Bainbridge. From time to time the official view is expressed in HM circulars to which, in general, Boards are required to work. The circulars are advisory, unless printed on pink paper, rather than mandatory for the most part and one may say at once that the advice in them is usually well considered and acceptable. It is necessary, as in everything, to be flexible in applying basic reasoning to local peculiarities and local geographical features. For my own part, I think that the Department circulars on the accident services are sound, perhaps because they bear strong resemblances to the views of the first Accident Committee of this Board 10 years ago.

Trouble, as always, occurs in trying to apply these sound principles for a variety of reasons. For one thing money is usually involved, i.e. more money for further building and physical facilities which are often deficient, and so often at the end of an HM advocating some very good improvements in the service comes the little chorus which says that no additional finance can be spared to implement the contained suggestions. I have often thought what an ideal song and refrain for a hospital Christmas show this would make-'The Minister's Song'.

To be fair, this has not been quite so marked of late, especially in relation to subjects which have acquired a pressure group and become the 'in thing', such as the care of the mentally subnormal at the moment, and surely there is a hint here for the accident services which in fact deal for the most part with the most socially valuable section of the community and certainly the most economically valuable.

This regional board's concern for the accident services officially goes back to a report, brought out in 1962, of a committee set up under the chairman- ship of Mr Dennis Wainwright of Stoke-on-Trent with a membership covering the specialties concerned with accident handling and the treatment of casualties in hospitals-orthopaedic surgeons, general surgeons and the staff of the accident hospital.

I had the good fortune to serve on that committee, being at that time practising in general surgery with a large trauma commitment. The findings of that committee were accepted by the Regional Hospital Board as a sound basis for future development. The original report has now twice been updated to match current developments and to take account of staffing attitudes and will need to be updated again to take account of the coming Area Health Board organization but seems to us to be still perfectly sound in its basic concept.

The report may be summarized under the few headings:

(i) So far as the hospital reception and treatment of major trauma is concerned, the best service to the public is provided by concentrating such work into departments of a size capable of supporting an adequate staff, so ensuring that a consultant-led team of the accident department is on duty to receive cases at all times, the members of the team being involved at the appropriate levels of responsibility.

(ii) Such a department so staffed should have control of its own in-patient beds and operating theatres. We have, I think, gone quite a way down this road by now except in relation to operating theatres, which tend to lag behind.

(iii) Such a department should be in a large district hospital which would be able to provide the necessary 24-hr pathological services, X-ray and immediate access to consultant advice and the assistance of other specialties for complex multiple injuries.

We recognize that local hospital and town pride could at times militate against bringing such a scheme to fruition. No doubt there will always be strong local personalities who want a doorstep facility in all communities without giving due thought to the effect this has in fragmentation of resources, especially of skilled staff. Since a large district hospital is already geared to a continuous 24-hr cover of emergency work the committee thought this preferable to specialized accident hospitals working 
in isolation which would face increasing problems in staffing supporting services. I think the experiences of our colleagues at the Birmingham Accident Hospital would, by and large, support this view. The report also expressed the view that it was felt that accident work alone would not attract many senior staff. In order to ensure a supply of good calibre staff it would be desirable to combine traumatic work as part of another specialty but that at least one of the team of consultants involved in accident work should have administrative responsibility to organize and to keep the service going in their hospital area. This, it was suggested, was a legitimate interest of the orthopaedic surgeons. Perhaps in these surroundings it is rather like scoffing at Jove in Olympus but for my own part at that time, I was a little reserved for it did seem to me then that the thought behind this concentrated too much on bone and joint injury aspects of trauma. Major trauma, especially the high velocity impact, affects the whole person, and the general surgeon dealing with severe infections, obstructuions and vascular lesions had more experience in such things as electrolyte balance and blood volume effects, for example, than did the orthopaedic surgeons. Some felt that there should be a race of emergency surgeons dealing not only with trauma, but also the usual surgical emergencies, but may I ask in what way does this differ from the traditional work of a general surgeon, which was always $60-65 \%$ emergency and trauma, except in some very selective institutions? However, the point is most probably academic, so long as the person concerned has other advice available, and will use it, for it is certain that there must be one overall doctor looking after the whole patient, as in the relationships between doctors caring for patients in an intensive therapy unit.

The Board's views on the hospital end of the trauma service then remain that major trauma should be handled in such circumstances. This is now gradually coming into shape with the development of the specialist district hospitals adequately loaded and sized for a sufficiently large population to warrant provision of 24-hr consultant teams and independent ward and theatre accommodation for trauma. But, hospital in-patient treatment of major trauma is only one aspect of accident work and if we add the other heading of our Conference, namely casualty, then the floodgates certainly are open.

In the first case, how does one decide what is major trauma appropriate to the accident unit of the main hospital? Some cases are quite obvious. Others are doubtful and as a crude filter we suggest that anything ambulance-borne should go direct to the main unit. Staging filters give rise to delay rather than to advantage to the seriously ill patient but if these filters are abolished the main centres must accept the trivia which such filters previously treated. It would appear that the inevitable delay between the infliction of the injury and bringing the patient and the doctor together is better spent in transit in an ambulance, provided that the crew are adequately trained and the vehicle is properly equipped. Failing this, the patient is staged through an often intermittently staffed accident room at a small hospital where the medical staff and sometimes the nursing staff are on call, rather than on duty and are not necessarily staff of the accident service but juniors of another discipline doing a stint on the casualty rota. As you will have observed we are of the view that a necessary corollary to this approach is that the ambulance service is given proper recognition for the importance of its role for the training of its personnel and adequate funding for this and for its vehicles and equipment. And training surely must mean continuous training as well as initial training however good that initial training is.

It does seem to us that the distance travelled in such an ambulance in the geographical context of this region is quite insignificant. Thirty to 40 miles would cover transit to main centres from any part of the region. What is more important would seem to be the time involved in some of the more remote spots in getting a trained crew to the site in the first place. Here we do try to involve local general practitioners with an interest to work up the service of local care as has been so ably demonstrated by Dr Easton in the North Riding. We do, however, think that such practitioners should be attached as clinical assistants to the area accident centre and work with the hospital staff. This is one of the areas where the present division of the medical services of the National Health Service operates disadvantageously, for, although several doctors in the region are interested, yet the time involved for them would be not inconsiderable, and adjustment against their normal practice needs is sometimes impossible. Nor can we, so long as the general practitioner is regarded as an independent contractor to the Executive Council, provide him with equipment which we would like to do: protective clothing, helmet, radios and the like, except when we can involve him in hospital work and arrange things a little, as with drug supplies and sterile supplies.

This brings us on to the next phase of the service for the injured. What about the walking wounded? It does seem to us that it could be unreasonable to require a patient who has cut his finger at say Stratford-on-Avon or Ross-on-Wye to travel to a main centre. You will say with merit that it is surely the function of a general practitioner to deal with this type of work and to decide whether the patient has cut his tendon and should go on to the main centre. But, I do submit that here we can anticipate 
the setting up of properly equipped and sufficiently large health centres with their associated general practice and community in-patient services where it is opportune, and, again by clinical assistantships, to provide such facilities and calling facilities to the doctor on rota for this type of work. Trivial yes, but often potentially dangerous, and by providing this type of facility in those former general practitioner and small country hospitals which we have, and which are likely to become these large health centres, a valuable service is given. This we have done, or have morally supported, in such places as Stratfordon-Avon, Bromsgrove, Redditch and Bridgnorth; we would like to go further but I think that the will has to come locally in the first place. One cannot drive everything from the centre, there has to be a pull from the periphery too. You will be aware that there is still a gaping chasm in this short review of the Board's ideas in this field. The old-style large casualty department in a town or city area was traditionally in the past, all the medical service the local population ever knew. With the increase in car ownership and the facility for calling out an ambulance by a 999 call (at one time an ambulance would only turn out at the request of a doctor or a policeman), it is now accessible to a much larger population. The non-resident general practitioner is also in increasing difficulty especially with the slowness in developing large health centres with group practices.

Although this department is now styled the Accident and Emergency Department it functions for the most part in just the same role as it did 40 years ago. The anticipation that with the advent of the National Health Service everyone would have a general practitioner as his first line of advice and would not need casual treatment by the local hospital does not seem to have materialized. Furthermore, in the past most such departments had a casualty officer on a semi-permanent basis running them and junior staff were often newly qualified doctors who had to do a certain proportion of their house surgeon post as a casualty house surgeon. In my own hospital for example, the house surgeon post was 9 months, of which the first 3 months had to be spent in the casualty department. We have tended to abandon this and have split the work of such departments into receiving room work for the accepted emergencies referred by general practitioners on their way to the appropriate receiving team (this is properly received by the first-line doctor of that team) and the work of the 'casualty' department. This I think is logical, and right. But what of this unheralded work; general practitioner type work arising from patients who either have no doctor or cannot get a response from their doctor or who have just not bothered to try to get their doctor; sudden illness in public places; unheralded emergencies brought in directly by police or ambulance and requiring not only diagnosis and sorting but also quite often fairly urgent initiation of treatment before handing over to the appropriate specialty department, a sort of hospital general practice if you like? Is it right to regard this as a rota duty of the accident firm? Is it right to regard it as a duty shared by all the housemen? From the point of view of the professional experience of a youngdoctor, it almost certainly is, providing he is adequately taught on the material, but from the point of view of conflict with other duties it is often an imposition. In any case who looks after the department and its administration and the teaching that is possible within it? Who trains the juniors not only in the short cuts of diagnosis but what is often much more necessary to a young doctor, in the routes of disposal and the access to the services not only hospital, but also community? We are trying several ways to achieve this. From the point of trying to obviate the inappropriate general practitioner work, we have approached several Local Medical Committees who are just as aware of this crisis of confidence between the public and the general practitioner as we are. Official records of complaint, I think, do not reflect the true position, as patients have a tendency not to complain. In several areas we are mounting joint publicity between the hospital, the Executive Council and the Local Medical Committee to the effect that-if you are ill your first approach is to your family doctor and this is how you get in touch with him out of normal hours'. Perhaps we should offer a communication facility to the duty general practitioner from the hospital. Along with this must go a process of training doctors' receptionists who have quite wrongly tended to become in some instances, a sort of preliminary diagnostic service. In the department itself we encourage the employment of general practitioners to the maximum possible and we are making, as a trial, appointments as described by Dr Bainbridge. Such appointments of consultant status would be a sort of hospital general practitioner with sufficient knowledge to carry out rapid sorting of cases, train the juniors and hold the administrative cords together. I would suggest that the basic philosophy of such a consultant post is not necessarily surgical but can equally be medical and anaesthetic, particularly anaesthetic. In our city hospitals some $45 \%$ or more of attenders are, in fact, suffering not from trauma but general medical, surgical or gynaecological conditions. This figure varies geographically; it seems that the further in you are to a large conurbation the higher it is. For example in Shrewsbury, I think this figure is only in the order of $15 \%$ whereas some of the London figures are as high as $70 \%$. It does seem rather odd to call 'experimental' a type of post which existed 40 or more years ago and 
which still exists in many places, but without the recognition that such a doctor deserves for his particular skill. Perhaps the 'experimental' aspect lies in the open-ended form of the post as to whether such a doctor has access to in-patient beds for continuing care or whether he is concerned with triage, initiation of treatment and such out-patient manoeuvres only. This again, is not new after all; the junior members of the honorary staffs of the former voluntary hospitals were usually appointed physician or surgeon to out-patients in the first place and access to beds depended on one's relationship with one's chief. I am not advocating this. I am only reminiscing.

Finally, we should not restrict ourselves to dealing with the injury after it has occurred. Anyone organizing an accident service should be equally concerned with the prevention of accidents and supporting those safety officers concerned, even if this amounts to little more than being available for advice. 